\title{
Spinal anesthesia and infraclavicular brachial plexus block for upper extremity reconstruction requiring grafting
}

\author{
Mustafa Turan ${ }^{1}$, Suleyman Kaya ${ }^{1}$, Suleyman Tas $^{1}$, Atakan Bas ${ }^{1}$, Handan Gulec ${ }^{2}$, Mehmet \\ Sahap ${ }^{2}$, Ezgi Erkilic ${ }^{1}$, Abdulkadir But ${ }^{2}$
}

1- Ankara Bilkent City Hospital, Üniversiteler, Bilkent Blv. No 1, 06800 Çankaya/Ankara, Turkey.

2- 2-Ankara Yildirim Beyazit University, Kızılca Mahallesi, 06760 Çubuk, Ankara, Turkey

Correspondence: Handan Güleç; Phone: +90 5056725948; E-mail: handandrhandan@yahoo.com.tr

\section{Abstract}

Combined use of upper limb blocks in the same surgery with lower limb central blocks is rarely performed due to the risk of systemic toxicity of local anesthetics. Therefore, general anesthesia is generally preferred in such surgeries. However, the use of ultrasound provides reliable anesthetic accumulation around the nerves, thereby reducing the need for local anesthetics, furthermore local anesthetic is used in spinal anesthesia compared to epidural anesthesia is much less. In this case report, a 32 year old male patient with ASA-1 score who underwent upper extremity reconstruction with a skin graft to be taken from the side thigh under spinal anesthesia and ultrasound-guided infraclavicular brachial plexus block. Both the peripheral block and the central block were successful and no complications related to the blocks were observed. We think that combining spinal anesthesia with ultrasound-guided infraclavicular brachial plexus block is a clinically useful and safe technique and is an alternative method of anesthesia for reconstruction of the upper limb requiring skin grafts.

Keywords: Analgesia; Nerve block; Pain; Reconstuction; Ultrasonography

Citation: Turan M, Kaya S, Tas S, Bas A, Gulec H, Sahap M, Erkilic E, But A. Spinal anesthesia and infraclavicular brachial plexus block for upper extremity reconstruction requiring grafting. Anaesth. Pain Intensive Care 2020;24(4):460-462.

Received: 20 May 2020, Reviewed: 31 My 2020, Revised: 29 June 2020, Accepted: 29 June 2020

\section{Introduction}

Regional anesthesia (RA) offers several advantages over general anesthesia (GA) for upper limb orthopedic surgery. One of the advantages is an improvement in postoperative pain, which results in reduced postoperative opioid needs and reduces recovery time for patients. ${ }^{1}$ The brachial plexus block with infraclavicular technique has a very common use. With upper limb nerve blocks accompanied by ultrasonography (USG), the technique has become relatively easier and complications have gradually decreased. ${ }^{2}$ Infraclavicular block; It is the USG guided upper extremity nerve block method by applying a local anesthetic agent around the axillary artery for surgery of hand, wrist, and forearm. The first factor that highlights the infraclavicular block;reduction of pneumothorax risk with newly defined approaches, the other one; it provides convenience in cases where catheters should be inserted. Lateral sagittal approach is known to be easy and safe in infraclavicular block.

\section{Case Report}

An ASA I male patient, 32 years old, $80 \mathrm{~kg}$ in weight, $175 \mathrm{~cm}$ tall, who had amputated from the left hand 23 th distal metacarpal as a result of gunshot wound, was taken from the emergency room to the operation room with stable hemodynamics. $0.05 \mathrm{mg} / \mathrm{kg} \mathrm{mg}$ i.v. Sedation was performed with midazolam, and it was decided to apply an USG guide brachial plexus block and central block with spinal anesthesia for graft because its hunger was not appropriate. After applying spinal anesthesia with $10 \mathrm{mg}$ hyperbaric bupivacaine in a sitting position, the supine position was placed and the head was turned across to the area that 
infraclavicular block be applied, and the arm was adducted and placed on the patient's chest in flexion. Following the disinfection of the area, a $100 \mathrm{~mm} 22 \mathrm{G}$ nerve stimulator needle (Stimuplex ${ }^{\circledR}$; Braun, Melsungen, Germany) was entered into the skin from the point where the clavicle and the coracoid protrusion intersect, as suggested by Klaastad et al. and as clinically practiced by Koscielniak et al. The axillary artery was visualized with lateral sagittal infraclavicular method accompanied by ultrasonography (USG). A mixture of $20 \mathrm{ml}$ of $0.25 \%$ bupivacaine and $10 \mathrm{ml}$ of $1 \%$ prilocaine was given by frequent aspirations, using a single injection method,10 minutes later, we tested that our block was successful with the pinprick test and told them to start the operation. One hour after the start of the operation, STSG (split-thickness skin graft) was taken from the left thigh, and was reconstructed simultaneously with the reverse flow radial forearm flap. No additional analgesic was required in the perioperative period. Sedation with $0.5 \mathrm{mg} / \mathrm{kg}$ ketofol was performed hourly with a ramsey scale of 3 . The operation lasted $5 \mathrm{~h}$. No intraoperative and postoperative complications developed. He was sent to the postoperative service.

\section{Discussion}

Regional anesthesia techniques are considered safer than general anesthesia under appropriate surgical conditions. ${ }^{3}$ Brachial plexus block is a very suitable regional anesthesia technique in forearm and hand surgery, since it provides a good introperative anesthesia and a very long postoperative analgesia according to the duration of action of the local anesthetic used. Evidence of successful upper limb peripheral nerve block includes arterial vasodilation, an increase in skin temperature, and an increase in blood flow through the brachial artery on the blocked side. In evaluating block success, clinicians usually use traditional evaluations such as pinprick test, hot / cold test that require verbal confirmation from patients and Bromage scale. ${ }^{4}$ We also applied the pinprick test to start the operation in our case. The brachial plexus is blocked by interscalene, supraclavicular, axillary and infraclavicular approaches with USG. The use of USG during the block simultaneously provides the needle, nerves, pleural and vascular structures to be protected and the distribution of local anesthetic during injection to be seen. ${ }^{5}$ Less needle movements compared to nerve stimulation method also increases patient comfort and acceptability of the procedure. ${ }^{6}$

There is a higher rate of phrenic nerve paralysis in the interscalene approach, and pneumothorax risk in the supraclavicular approach so lateral sagittal infraclavicular approach was preferred instead of these pathways, which is less complicated and is commonly used in our clinic. Modern infraclavicular technique was reported in 1973 by Raj et al. However, in this technique, since the plexus is blocked at more superficial points, it can cause discomfort in patients. However, an inevitable trap of this method is the right angle between the needle and the ultrasound probe, which makes needle visibility difficult. ${ }^{7}$ Koscielniak et al. stated that lateral sagittal infraclavicular (LSIB) approaches are less painful and easily acceptable to the patient than axillary methods requiring multiple injections. ${ }^{8}$ It can be preferred especially in cases where shoulder movements are limited or in cases where catheter needs to be inserted. Based on this information, we implemented a block using the lateral sagittal method and did not experience any complications. Graft can be removed with peripheral block application of the lower limb, but spinal anesthesia can be applied to avoid excessive local anesthetic dose. We, the anesthetists, kept the volume high for the effect to last longer.

\section{Conclusion}

We think that combining spinal anesthesia with ultrasound-guided infraclavicular brachial plexus block is a clinically useful and safe technique and it is an alternative method of anesthesia for reconstruction of the upper limb requiring skin grafts.

\section{Conflict of interests}

None declared by the authors.

\section{Authors' contribution}

All authors took part in the case management and the manuscript preparation.

\section{References}

1. Casati A, Danelli G, Baciarello M, Corradi M, Leone S, Di Cianni $S$, et al. A prospective, random-ized comparison between ultrasound and nerve stim-ulation guidance for multiple injection axillary bra-chial plexus 
block. Anesthesiology. 2007;106(5):992-996. [PubMed] DOI: $10.1097 / 01$.anes.0000265159.55179.e1

2. Gürkan Y, Acar S, Solak M, Toker K. Comparison of nerve stimulation vs. ultrasound-guided lateral sagittal infraclavicular block. Acta Anaesthesiol Scand. 2008;52(6):851-855. [PubMed] DOI: 10.1111/j.13996576.2008.01655.x

3. Gharaei $H$, Khan TH. Is regional anesthesia safe in children? Anaesth Pain Intensive Care. 2014;18(1):3-5 [Free Full Text]

4. Özyalçın SN, Erdine S. Üst ekstremite so-matik blokları. Rejyonel Anestezi. Nobel Tıp Kitabe-vi:İstanbul; 2005.

5. Schulz-Stübner S. Brachial plexus. Anesthe-sia and analgesia. Anaesthesist. 2003;52(7):643-656. [PubMed] DOI: 10.1007/s00101-003-0532-9
6. Gürkan Y, Acar S, Solak M, Toker K. Comparison of nerve stimulation vs. ultrasound-guided lateral sagittal infraclavicular block. Acta Anaesthesiol Scand. 2008;52(6):851-855. [PubMed] DOI: 10.1111/j.13996576.2008.01655.x

7. Klaastad Q, Smith HJ, Smedby O, Winther- Larssen $\mathrm{EH}$, Brodal $\mathrm{P}$, Breivik $\mathrm{H}$, et al. A novel infraclavicular brachial plexus block: the lateral and sagittal technique, developed by magnetic resonance imaging studies. Anesth Analg. 2004;98:252-256. [PubMed] DOI: 10.1213/01.ane.0000094337.75996.ae

8. Bruce BG, Green A, Blaine TA, Wesner LV. Brachial plexus blocks for upper extremity orthopae-dic surgery. J Am Acad Orthop Surg. 2012;20(1):38-47. [PubMed] DOI: $\underline{10.5435 / J A A O S-20-01-038}$ 